\title{
The Effects of the Process Approach on High School Students' Writing Performances
}

\author{
Pham Vu Phi Ho ${ }^{1}$, Nguyen Minh Thien ${ }^{2}$, Tran Thi Thuy Oanh ${ }^{3} \&$ Do Thi Phuong Trinh ${ }^{4}$ \\ ${ }^{1}$ Baria Vungtau University, Vung Tau City, Vietnam \\ ${ }^{2}$ Faculty of Foreign Languages, Dong Nai Technology University, Dong Nai province, Vietnam \\ ${ }^{3}$ University of Foreign Languages Studies, The University of Da Nang, Vietnam \\ ${ }^{4}$ Huynh Man Dat High School, Kien Giang, Vietnam \\ Correspondence: Pham Vu Phi Ho, Baria Vungtau University, Vung Tau City, Vietnam. E-mail: \\ hopvp@bvu.edu.vn
}

$\begin{aligned} & \text { Received: December 19, } 2019 \\ & \text { Accepted: March 4, } 2020 \quad \text { Online Published: March 10, } 2020 \\ & \text { doi:10.5539/ijel.v10n2p406 }\end{aligned}$ URL: https://doi.org/10.5539/ijel.v10n2p406

\begin{abstract}
Quite a few research studies have been conducted to investigate whether the writing process approach has any effects on students' writing quality in higher education. However, few studies have been conducted at a talented high school in a remote area in Vietnam to see whether it works in the same manner where students' writing skills in paragraph levels were very low. The purpose of this study is to examine the effects of the process approach on enhancing EFL students' writing performance in terms of fluency and accuracy. The target subjects were from grade twelve, Huynh Man Dat (HMD) High School at Kien Giang City, Vietnam. Sixty students from the control and experimental groups enrolled in this course as a normal curriculum of the school. The research instruments are the writing tasks, used as the pre-test and post-test. Data collection was from pre-tests, post-tests, and word-count from all essays of students to measure their writing fluency. Pre-tests and post-tests were compared to see if there were any differences in writing performance between the two groups. The students' writing performance was evaluated using analytical scoring on the composite scores and the two aspects of writing which are fluency and accuracy. The results of the study set lights to teachers at HMD high school to consider to use this effective approach in their writing classrooms.
\end{abstract}

Keywords: writing performance, writing fluency, writing accuracy, process approach

\section{Introduction}

Writing skill is one of the fundamental skills that most of the EFL/ESL students need to be fluent. Writing skill involves composing, which means having the ability to tell or retell pieces of information in the form of narratives or description, and transforming information into new texts, as in expository or argumentative writing. Writing is unlike speaking language in which it requires the reader or the audience to understand and interpret what has been written. Therefore, many students at high school find it difficult to improve their writing skills after they have learned English for years. According to Brown (2001), writing should be a learning process in which students interact and communicate with each other, learn from their peers and share ideas to have a good atmosphere for learning. As a result, writing is no longer a way to transmit a message but "a way to grow and cook a message". Through group work activities, students can co-operate with each other in brainstorming, discussing, and sharing ideas. Peer conferencing and written peer response help students to improve negotiation and social skills, such as producing a story or a report in groups. Pham et al. (2020) claimed that part of the writing process, peer feedback activities actually help students learn from one another and enhance their writing outcomes.

The low standards of English language learning among high school learners is one of the urgent issues drawing lots of researchers' attention in Vietnam as well as in other parts of Asia. Especially, students find it difficult to improve their skills in the writing section. As a difficult skill for students to improve, writing is not a simple cognitive activity; however, as Grami (2010) stated, it is like a complex mental production that consists of careful thought, discipline, and concentration. As stated by Swain (2001), group work activities to complete communicative tasks engage students in their writing tasks. Cooperative writing tasks need students to work together from brainstorming to composing a finished product. Additionally, cooperative in writing tasks such as 
peer feedback help students improve their writing quality (Pham \& Usaha, 2016; Pham, 2019). The joint writing activity pushes learners to reflect on language, discuss the language they are using, and cooperate with each other in the solution of the linguistic problems they meet. Sociocultural researchers say that collaborative tasks facilitate L2 learning and encourage students to write.

In order to investigate whether the writing process approach had any effect $g$ on developing university students' essay writing skills, Alodwan and Ibnian (2014) employed a quasi-experimental study on two groups at the World Islamic Sciences and Education University in Amman. Data collection was from the pre-test and post-test to see if the writing process affected the students' writing skills. The study revealed that during the process approach such as pre-writing, drafting, revising, editing, and publishing, the students had chances to explore, generate new ideas, and improve their writing in terms of ideas and mechanics of writing. The students in the experimental group performed much better on the post-essay writing tests than those in the control group. Hence, the writing process approach had significantly positive effects on developing university students' essay writing skills. This study did not investigate whether this writing approach had effects on students' writing fluency.

Bayat (2014) investigated the effect of the process writing approach on writing success and anxiety. 74 students first-year preschool teaching at Akdeniz University, Faculty of Education participated in the study. 38 students were assigned to the experimental group while 36 were in the control group. The study employed a quasi-experimental design for 10 weeks. Data collection was from the pre-test and post-test to evaluate the students' writing outcomes and from the Writing Apprehension Test. Data associated with writing anxiety were collected through the Writing Apprehension Test. The study found that the process writing approach had a significant effect on writing scores and anxiety. Based on this finding, the use of the writing process approach is recommended for written expression studies. This study did not clarify if the process approach had any effects on the students' writing fluency.

Faraj (2015) conducted a study at Koya University to investigate the effects of the writing process on the students' writing ability. Thirty 2 nd year students from the English Language Department participated in the study. The research design was single-group pre-test vs. post-test. The study made use of the process approach to train students on how to write through activities such as prewriting, drafting, revising, editing and publishing. Data collection was from the pre-test and post-test, and student feedback. The findings of the study revealed that the students' writing abilities in the post-test were significantly different compared to those of the pre-tests. The students expressed that they could express their ideas confidently in writing. This study did not investigate the effects of the writing process approach on students' writing fluency.

Have been found that the effectiveness of using the process approach to teach writing is still inconclusive, Ho (2006) investigates how effective process writing is in helping about 200 students at the upper primary school level and the lower primary school level improve their writing skills and their attitudes towards writing. The researcher uses post-interviews and the comparison of a pre- and post-questionnaire. The study revealed that the employment of the writing process approach helped students improve their writing performances. It helped the students learn how to use the strategies at each stage of the process of writing. Also, the students obtained positive attitudes toward writing. The study suggested that the process approach is an effective approach in primary school. In terms of accuracy, this study was not explicitly measured.

Previous research studies seemed to be successful in employing the writing process approach to train students on how to write. However, a specific measure on the effects of the writing process approach on the students' writing fluency was not totally explored. The primary focus of the present study was to investigate whether the writing process approach had any effects on the students' writing accuracy and fluency. The writing fluency in this study was measured by the number of words written in each essay by the students. The current study was an attempt to respond to the following research questions

\section{Research Question}

1) Does the writing process approach have any effects on students' writing accuracy?

2) To what extent does the writing process approach have any effect on students' writing fluency?

\section{Methodology}

\subsection{Setting \& Participants}

Convenience sampling (also called availability sampling) was used in the study, which was a technique where subjects were selected due to their convenient accessibility and proximity to the researcher. Two intact classes were chosen with 60 students of the two English classes among 330 students in grade 12 from a high school in Kien Giang participated in this study, including 40 females and 20 males. The students in these two classes had a 
similar level of English and had been learning English for 10 years. They were all specialized in English and used the same textbook that is Tieng Anh 12, which was the third and also the last of the three-level English language set of textbooks for the Vietnamese upper secondary school, which followed the curriculum approved by the Ministry of Education and Training in November 2012. It was also known as textbooks for a ten-year program or pilot program. In this textbook, students were expected to write argumentative essays, letters, and CVs. Argumentative essays are the most difficult for the students at HMD high school.

\subsection{Research Design}

In this study, quasi-experiment research was used to investigate the effects of process writing on high school students' writing performance. The study adopted the quantitative research methods.

This study was conducted on the experimental group and the control group using a quasi-experimental design. The training of the control group was in such a way that all the activities designed in the text-book were implemented in the classroom. These included filled in the banks, did exercises in the text-book, and learned some grammatical points relating to the writing assignments. In the experimental group, the researcher/teacher employed the writing process approach to teaching the students. The researcher/teacher used group-work activities to help students brainstorm ideas together before they composed essays. Peer feedback was also employed in the classroom. These activities took an amount of time in the classroom, so the activities designed in the text-book were ignored in the experimental group. This was the difference in training between the two groups of the study.

The researcher carried out the study for 14 weeks. The study consisted of 4 stages. Stage 1: week 1 was used to administer the pre-test for the writing task. The pre-test was used for both groups in 45 minutes. Stage 2: week 2 is for orientation stage: prior to the experiment, all participants were given an orientation, covering such areas as how to improve students' writing skills, how to record their writing and the teachers' expectations. Stage 3: 10 weeks later were then allotted for the execution of the process learning lesson plans, applying peer activities, such as brainstorming, group writing, peer response, drafting, revising, and editing in the writing process. Stage 4: The final two weeks were used to administer the post-test which was used for both groups to compare the results of students' creative writing of these groups.

\subsection{Data Collection and Analysis}

The researcher used pre-test, post-test, and questionnaire to collect data. The data were collected in accordance with the two stages of the experimental teaching: (i) students' performance before and after the employment of the process approach to train students' writing skills via the pre- and post-tests, and (ii) their reflections on the approach were revealed via questionnaires. The results of the pre-test were collected during the second week, while the post-test results are analyzed during week 14 . First, the researcher counted the words of every essay to know the length of their writing. Second, common errors that were seen as most frequent errors appeared in the students' writing. In addition, scoring rubrics were used to measure students' writing accuracy. A rubric is a scoring tool used to evaluate students' writing performance, which is adapted by the EFL Teaching group at Huynh Man Dat High School. Quantitative analysis using a t-test to compare the writing performance of the experimental group. Independent sample t-tests and paired sample t-tests were run to determine whether there was any difference in writing fluency and accuracy between the experimental \& control group before and after the use of the writing process.

\section{Results/Findings and Discussion}

The purpose of this section was an attempt to seek the answers to the two research questions. First, I compared the results of the pre-tests of both groups to see if there were any differences of students' writing performances in terms of accuracy and fluency; then I compared the results of the pre- vs. post-tests of the two groups to see if there were any differences after the treatments. The pre-test and post-test were run to compare if there was any significant difference in terms of fluency and accuracy after the treatment. The 2 inter-raters marked the students' writing papers based on the given scoring rubrics. Also, the inter-rater reliability was checked.

There were 120 writing papers collected and evaluated in this study. In particular, the control class had 60 papers, including 30 of pre-tests and 30 of post-tests. The mean scores of the 30 pre-test papers had an average of 170 words per paper $(\mathrm{M}=170.2 ; \mathrm{SD}=17.35)$; and the 30 post-test writing papers of the control class had an average of 173 words per essay $(\mathrm{M}=172.5 ; \mathrm{SD}=15.08)$.

Besides, the experimental group had 60 papers, including 30 writing pre-test papers with 171 words per essay $(\mathrm{M}=$ $358.71 ; \mathrm{SD}=73.48)$ and 30 writing post-test papers with an average of 195 words per essay $(\mathrm{M}=194.50 ; \mathrm{SD}=$ 15.35). 
The results of the writing papers are shown as follows

\subsection{Research Question 1: Does the Writing Process Approach Have Any Effects on Students' Writing Accuracy?}

\subsubsection{Writing Accuracy Before the Treatment}

The mean score of the 30 writing tests of the control group and the mean score of 30 papers of the experimental group in the first test (pre-test) were compared and analyzed by SPSS software version 22. Independent Sample t-test was run to compare the results of two groups to see if there was any difference between English writing skills and the quality of the 2 groups of students before being intervened by the implementation of the process writing method. The Cronbach's Alpha for inter-raters of the control group at the pre-test was .979 , and that of the experimental group was .977 . Table 1 presents the comparison of the pre-tests between the control and experimental group.

Table 1. Students' writing accuracy before the experiment

\begin{tabular}{llllll}
\hline Variable & $\mathrm{M}$ & $\mathrm{SD}$ & $t$ & $d f$ & $\mathrm{p}$ \\
\hline Writing accuracy & & & & & \\
$\quad$ Experimental Group & 5.75 & 1.331 & -0.48 & 58 & .962 \\
$\quad$ Control Group & 5.76 & 1.343 & & & \\
\hline
\end{tabular}

Note. $*$ The $t$ and $d f$ were not adjusted because variances were equal.

* Independent Samples t-test.

Table 1 compared 30 essays written by the control group and 30 essays by the experimental group using the Independent Samples t-test. On average, each student in the control group gained score $5.76(\mathrm{M}=5.76 ; \mathrm{SD}=1.34)$ and each student in the experimental group achieved 5.75 score $(\mathrm{M}=5.75 ; \mathrm{SD}=1.33)$. The mean score of the control group was slightly higher than the experimental group (5.76 vs. 5.75). However, the results of the Independent Samples Test showed that the two groups did not have significant differences in individual writing skills $(t(58)=-.048 ; p=.96 ; p>.05)$. This showed that the writing skills of the two groups before conducting the experiment were not different. The writing skills of students were considered equal. Thus, after conducting the experiment, if there were a difference between the two groups on writing skills, it was possible to predict (predict) the effects of the process writing method on the dependent variable (writing performance) in this study.

\subsubsection{After the Treatment}

After the treatment of employing the writing process approach to train the students' writing skills. First, (1) the results of the pre-test and the post-test of the control group were compared, then (2) those of the experimental group were also compared. After that (3) the results of the post-tests of these two groups were compared to see if there were any differences in writing performance after the treatment. Independent t-tests and Pair Samples t-tests were run to check the differences in students' writing skills. The Cronbach Alpha's of the experimental group's post-test was .985 and that of the control group was .988 .

\subsubsection{Comparison of Writing Accuracy Between the Control Group and Experimental Group}

In this section, the paired sample t-test was run, first, to test if there was any difference between the pre-test and the post-test of the control group. Then the pre-vs. post-test of the experimental group was compared. Finally, the post-tests of the two groups were compared by the independent sample t-test to test the hypothesis of the study to respond to the first research question. Table 2 presents a comparison between the pre- vs. post-test of the control group (CG).

Table 2. Writing accuracy of the pre-test and post-test of the control group

\begin{tabular}{lrrllll}
\hline Variable & $\mathrm{M}$ & $\mathrm{SD}$ & Correlation & $t$ & $d f$ & $p$ \\
\hline Writing accuracy of CG & & & & & & \\
Pre-test & 5.76 & 1.34 & .934 & -1.14 & 29 & .246 \\
Post-test & 5.86 & 1.22 & & & & \\
\hline
\end{tabular}

Note. Paired Samples T-test.

Table 2 illustrates the results of the comparison between the pre-test and post- test of the control group in terms of accuracy. On average, each student in the control group scored 5.76 on the pre-tests $(\mathrm{M}=5.76 ; \mathrm{SD}=1.34$ ), while in the post-test, each of them scored $5.86(\mathrm{M}=5.86 ; \mathrm{SD}=1.22)$. There seemed not to be much difference between 
the scores in two different conditions. The result of the paired sample t-test with $t(29)=-1.14, p=.26(p>.05)$ indicates that there was no statistically significant difference between the pre- vs. post-test of the control group. The null hypothesis was not rejected. That is, there was no statistical improvement in the writing accuracy of the students in the control group.

Next, the paired sample t-test was employed to compare the mean scores of the pre-test and post-test of the experimental group for accuracy. The main aim of this part was to determine whether the mean scores of this group before and after the intervention of the writing process method were different.

Table 3. Writing accuracy of the pre- vs. post-test of the experimental group

\begin{tabular}{ccccccc}
\hline Variable & $\mathrm{M}$ & $\mathrm{SD}$ & Correlation & $t$ & $d f$ & $p$ \\
\hline Writing accuracy of EG & & & & & & \\
Pre-test & 5.750 & 1.33 & .849 & -7.31 & 29 & .000 \\
Post-test & 6.733 & 1.34 & & & & \\
\hline
\end{tabular}

Note. Paired Samples T-test.

Table 3 reveals the comparison between the pre-test and post-test of the experimental group after the treatment of employing the writing process approach to train students; writing skills. As can be seen, of 30 written essay papers by 30 students, on average, each student of the experimental group in the pre-test gained 5.75 score $(\mathrm{M}=5.75 ; \mathrm{SD}$ $=1.33)$, while each of them received 6.73 scores in the post-tests was $6.73(\mathrm{M}=6.7 ; \mathrm{SD}=1.34)$. In addition, Paired Samples t-test results showed that there was statistically significant difference between post-test and pre-test scores as the $\mathrm{p}$-value of $\mathrm{t}(29)=-7.31, \mathrm{p}=.000(\mathrm{p}<.05)$. The data indicated that students' writing skill was remarkably improved. In other words, the writing process approach had a great effect on the students' writing accuracy.

Finally, the Independent samples t-test was run on the post-test to help compare the mean scores between two groups and identify if the students in the experimental group gained better improvement than those in the control group in writing performance in term of accuracy thanks to the intervention of writing process method.

Table 4. Comparison of the post-tests between the control and experimental group

\begin{tabular}{ccccccc}
\hline Variable & $\mathrm{M}$ & $\mathrm{SD}$ & Mean difference & $t$ & $d f$ & $p$ \\
\hline Students' writing accuracy & & & & & & \\
post-test EG & 6.73 & 1.35 & .866 & 2.6 & 58 & .012 \\
Post-test CG & 5.86 & 1.22 & & & & \\
\hline
\end{tabular}

Table 4 illustrates the major test to compare the mean score of the experimental group and that of the control group. As shown in Table 4, each student in the experimental group scored 6.73 in the post-test $\left(\mathrm{M}_{\mathrm{EG}}=6.73 ; \mathrm{SD}=1.35\right)$, whereas each student in the control group gained $5.86\left(\mathrm{M}_{\mathrm{CG}}=5.86 ; \mathrm{SD}=1.22\right)$. The mean difference between the two groups was .87. The result of the independent sample t-test $(t(58)=2.6, p=0.12, p<0.05)$ indicates that there was a statistically significant difference between the control group and the experimental group who scored in the post-tests. In other words, the mean score of the experimental group with the intervention of the process writing approach was higher than that of the control group. That is, the students in the experimental group gained a better quality of writing accuracy than the control group.

In brief, the results of the current study revealed that (1) at the beginning of the training when no treatment of writing process approach was implemented to the writing classrooms, there was no difference in writing accuracy between the control and experimental group. (2) after three months of the treatments of which the control group obtained the treatment based on the activities designed in the text-book, and the experimental group received the training with the employment of the writing process approach, the students' writing accuracy in the experimental group gained significantly improvement while this did not occurr in the control group. (3) In addition, the comparison of the post-tests between the two groups indicated that all the students in the experimental group remarkably outweighed the control group in writing skills. This confirmed the effects of the writing process approach had great effects on the students' writing outcomes. 


\subsection{Research Question 2: To What Extent Does the Writing Process Approach Have any Effect on Students' Writing Fluency?}

\subsubsection{Writing Fluency Before the Treatment}

As mentioned earlier, the term of writing fluency refers to the number of words (lengthy) of students' writing products. In this study, the students' writing fluency was measured by tallying the number of words written in the pre-tests and post-tests of the students of the two groups. The duration of writing tests took 45 minutes each.

Pre-tests of the control group and experimental group were compared. This result would contribute to the reliability of the above results in comparing the level of students' writing performance in two groups. To analyze this aspect, the Independent sample t-test was run to find if the null hypothesis was accepted before the intervention. Table 5 presents the fluency of students of the two groups in the pre-test papers.

Table 5. Students' writing fluency before the experiment.

\begin{tabular}{lllllll}
\hline Variable & M & SD & & $t$ & $d f$ & $p$ \\
\hline Fluency before the treatment & & & & & & \\
Experimental Group & 170.20 & 17.14 & 533 & .118 & 58 & .91 \\
Control Group & 170.73 & 18.01 & & & & \\
\hline
\end{tabular}

Note. The $t$ and $d f$ were adjusted because variances were not equal.

Independent Samples t-test.

Table 5 showed the average number of words in each essay written by the two groups. Each essay of the experimental group had 171 words per paper on average $(M=170.20 ; S D=17.14)$, the writing of the students in the control group seemed to be better with 171 words per essay on average $(M=170.73 ; S D=18.01)$. However, the value $p=.91(p>.05)$ of the Independent Samples-test showed that there is no significant difference in fluency between the two test groups. Thus, the author of this study, based on the comparison of writing accuracy in Table 1 and about writing fluency of students in Table 5 of the two groups, can make sure that students of the two groups in the study did not make any significant difference in both writing accuracy and fluency. In another word, participants from both groups had the same starting point. After experimenting with the process writing method, if there are any differences, it can be summarized that the experimental method affects.

\subsubsection{After the Treatment}

To answer research question 2, the researchers had to do some of the following. First, (1) the researchers compared the results of the pre-test and the post-test of the control group, (2) then the results of the experimental group to see if there was difference in writing fluency after the treatment of the process writing method, (3) then the researchers compared the results of the post-tests of these two groups together.

Table 6. Students' writing fluency of the pretest and posttest of the control group

\begin{tabular}{lcclllll}
\hline Variable & M & SD & Correlation & Mean Difference & $t$ & $d f$ & $p$ \\
\hline Writing fluency & & & & & & & \\
Pre-test (CG) & 170 & 17.13 & .950 & -2.30 & -2.3 & 29 & .029 \\
Post-test (CG) & 173 & 15.08 & & & & & \\
\hline
\end{tabular}

Note. Paired Samples t-Test.

First, the results presented in Table 6 show the mean scores of students' writing fluency compared to the post-test by Pair Sample T-test to examine the improvement of students' writing fluency of the control group. The figures in Table 6 indicated that the mean score of the post-test in the text length of the students in the control group increased compared to pre-test $(\mathrm{t}(29)=-2.3, \mathrm{p}=.029<0.05)$.

Table 7. Students' writing fluency of the pretest and posttest of the experimental group

\begin{tabular}{llllllll}
\hline Variable & M & SD & Correlation & Mean Difference & $t$ & $d f$ & $p$ \\
\hline Writing fluency & & & & & & & \\
Pre-test (EG) & 170.7 & 18.00 & .597 & -23.7 & -8.5 & 29 & .000 \\
Post-test (EG) & 194.5 & 15.36 & & & & & \\
\hline
\end{tabular}

Note. Paired Samples t-Test. 
Next, as can be seen from Table 7, there was a significant difference between mean scores of the post-test and pre-test in text length of experimental group $\mathrm{t}(29)=-8.5, \mathrm{p}=.000(\mathrm{p}<0.05)$.

Thirdly, the Independent Samples t-test was run on the post-test to help compare the mean scores between two groups in terms of writing fluency and identified if the students in the experimental group gained better improvement than those in the control group in writing fluency thanks to the intervention of process writing method.

Table 8. Comparison of writing fluency of the two groups

\begin{tabular}{lcccccc}
\hline Variable & M & SD & Mean Difference & $t$ & $d f$ & $p$ \\
\hline Students' writing fluency & & & & & & \\
Post-test (EG) & 194.5 & 15.3 & 22 & 5.59 & 58 & .000 \\
Post-test (CG) & 172.5 & 15.1 & & & & \\
\hline
\end{tabular}

Note. Independent Samples t-test.

As shown in Table 8, there was a statistically significant difference in the mean scores on the post-test of the two groups. In the post-test result, the mean score of the experimental group with the intervention of the process writing approach was higher than that of the control group $\left(\mathrm{M}_{\mathrm{EG}}=194.5>\mathrm{M}_{\mathrm{CG}}=170.5\right)$. It is shown that the students in the experimental group achieve improvement of text length in writing text after the implementation of the process writing approach in comparison with those in the control group. According to statistics, the author of this paper can conclude that the students in the control group didn't achieve much improvement of text length in writing text after 14 weeks of study without using the process writing method.

As can be seen from the above findings, the mean score of the experimental group with the intervention of the process writing approach was higher than that of the control group in terms of writing fluency $\left(\mathrm{M}_{\mathrm{EG}}=194.5>\mathrm{M}_{\mathrm{CG}}\right.$ $=170.5)$ and writing accuracy $\left(\mathrm{M}_{\mathrm{EG}}=6.73>\mathrm{M}_{\mathrm{CG}}=5.86\right)$. Moreover, the findings showed there was a significant difference between the post-test mean score of the experimental group and that of the control group in writing accuracy $(\mathrm{t}(58)=2.6, \mathrm{p}=0.012<0.05)$ and writing fluency $(\mathrm{t}(58)=5.59, \mathrm{p}=0.00<0.05)$. As a result, the students in the experimental group achieve much improvement of text length and writing quality after the implementation of the process writing approach in comparison with those in the control group. According to statistics, the authors of this paper can conclude that the students in the experimental group had much more improvement in text length compared to those in the control group after 14 weeks of study with using the process writing method.

One finding the present study revealed that the process approach had great effects on the students' writing skills. It helped students enhance their performances. This finding was consistent with some other researchers such as Alodwan and Ibnian (2014), Faraj (2015), Bayat (2014), Yaylı (2009), and Nihat (2014). Another researcher such as Çakır (2003) who found that process approach help enhance students' writing content, organization, and techniques such as rhetorical structures, cohesion, grammar, and creativity. Pham and Do (2019) also found that the process writing approach helps students' writing papers improve in terms of fluency and accuracy. In a different aspect, Yayl1 (2009) claimed that the process approach applied to train the students on how to write help change students' negative views about writing.

The findings of the first research question of the study are consistent with some previous studies (e.g., Ho, 2006; Öztürk \& Çeçen, 2007). As Ho (2006) indicated that the process writing helped students improve their writing skills and their attitudes toward writing. Furthermore, Öztürk and Çeçen (2007) concluded that students' anxiety in writing no longer exist when they employed this kind of method to teach students writing skills.

\section{Conclusion}

The purpose of the current study was to investigate if the writing process approach had any effect on the students' writing quality in terms of writing fluency and accuracy. The writing fluency was measured by the number of words written in the essays, whereas the accuracy was measured via the scores of the pre- vs. post-tests rated by inter-raters. The findings of the study confirmed that employing the process approach to the writing classroom, the students were able to improve their writing skills. In other words, using the process approach to train students in the writing classroom had great impacts on their writing fluency as well as accuracy.

The current study had its merits to contribute to the body of knowledge. However, it also had some limitations. First, the current study only used quantitative data for analysis, but qualitative data. There should be more exploration for the next research to investigate the perceptions of the students to get in-depth information about the phenomena. Second, this was just a case study conducted at one university. It could not be generalized to 
other contexts.

\section{References}

Alodwan, T. A. A., \& Ibnian, S. S. K. (2014). The Effect of Using the Process Approach to Writing on Developing University Students' Essay Writing Skills in EFL. International Journal of Linguistics and Communication, 2(2), 147-163

Bayat, N. (2014). The Effect of the Process Writing Approach on Writing Success and Anxiety. Educational Sciences: Theory and Practice, 14(3), 1133-1141. https://doi.org/10.12738/estp.2014.3.1720

Brown, D. (2001). Teaching by principles: An interactive approach to language pedagogy. White Plains, Addison: Welsey Longman.

Çakır, Ö. (2003). Yazma öğretiminde süreç yaklaşımına dayalı programın yazılı anlatım becerisini geliştirmedeki rolü: Mersin Üniversitesi Eğitim Fakültesi örneği. TÖMER Dil Dergisi, 122, 31-51.

Faraj, A. K. A. (2015). Scaffolding EFL Students' Writing through the Writing Process Approach. Journal of Education and Practice, 6(13), 131-141.

Grami, G. M. A. (2010). The effects of integrating peer feedback into university-level ESL writing curriculum: A comparative study in a Saudi context.

Ho, B. (2006). Effectiveness of using the process approach to teach writing in six Hong Kong primary classrooms. Perspectives: Working papers in English and communication, 17(1), 1-52.

Öztürk, H., \& Çeçen, S. (2007). The effects of portfolio keeping on writing anxiety of EFL students. Dil ve Dilbilimi Çalışmaları Dergisi, 3(2), 218-236.

Pham, V. P. H. (2019). The Effects of Lecturer's Model e-comments on Graduate Students' Peer e-comments and Writing Revision. Computer Assisted Language Learning, in press 09 Jul 2019. https://doi.org/10.1080/09588221.2019.1609521

Pham, V. P. H., \& Do, T. P. T. (Dec. 2019). High School Students' Common Errors in Writing Essays. International Journal of English Linguistics, 9(6), 309-319. https://doi.org/10.5539/ijel.v9n6p309

Pham, V. P. H., \& Usaha, S. (2016). Blog-based peer response for L2 writing revision. Computer Assisted Language Learning, 29(4), 724-748. https://doi.org/10.1080/09588221.2015.1026355

Pham, V. P. H., Phung, L. T. K., Oanh, T. T. T., \& Giao, N. Q. (January 2020). Should Peer E-Comments Replace Traditional Peer Comments? International Journal of Instruction, 13(1), 295-314. https://doi.org/10.29333/iji.2020.13120a

Swain, M. (2001). Integrating language and content teaching through collaborative tasks. Canadian Modern Language Review, 58(1), 44-63. https://doi.org/10.3138/cmlr.58.1.44

Yaylı, D. (2009). Hizmet öncesi Türkçe öğretmenleri ile bir süreç yazma uygulaması. XVIII. Ulusal Eğitim Bilimleri Kurultayı, Ege Üniversitesi, İzmir.

\section{Copyrights}

Copyright for this article is retained by the author, with first publication rights granted to the journal.

This is an open-access article distributed under the terms and conditions of the Creative Commons Attribution license (http://creativecommons.org/licenses/by/4.0/). 